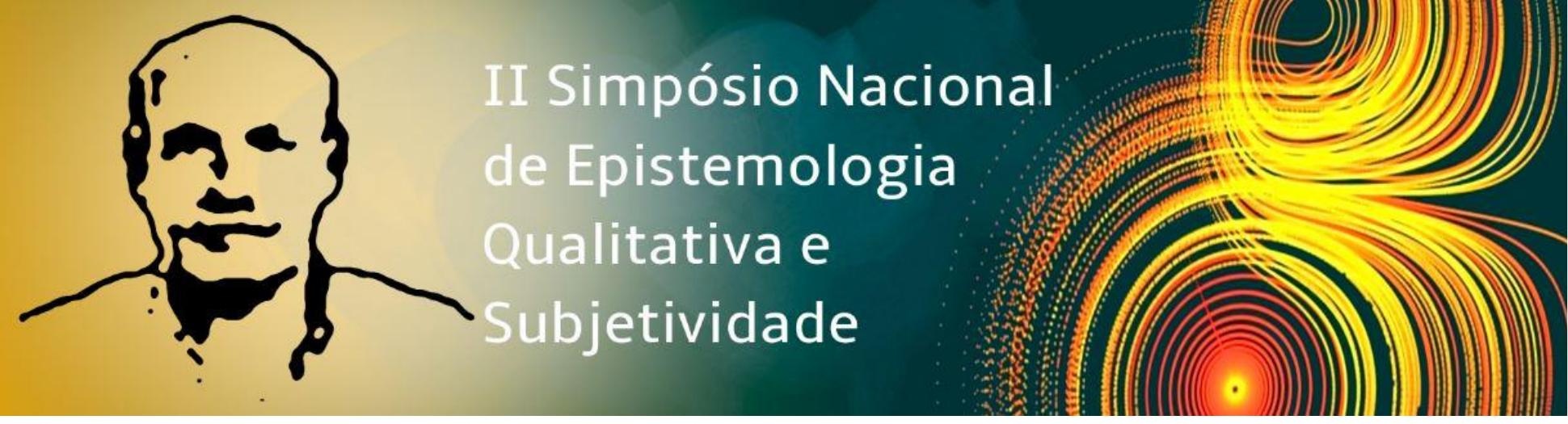

Eixo temático: Subjetividade e Saúde Humana

\title{
As novas formas de institucionalização e os caminhos uma clínica antimanicomial
}

Pedro Martini Bonaldo, Centro Universitário de Brasília - UNICEUB, pmbonaldo@yahoo.com.br Valéria Deusdará Mori Centro Universitário de Brasília - UNICEUB, valeria.mori@ceub.edu.br Resumo

No Brasil, a assistência à saúde mental vem passando por profundas mudanças nos últimos anos, sobretudo com a implementação dos serviços substitutivos ou a instalação da Rede de Atenção Psicossocial (RAPS) para extinção dos manicômios, dentro da reforma psiquiátrica. Grandes avanços foram feitos dentro da reforma psiquiátrica, com a o fechamento de diversos hospitais psiquiátricos, abertura de CAPS (Centro de Atenção Psicossocial) e implementação de serviços mais humanizados. Todavia isso não quer dizer que processos de institucionalização tenham sidos superados como demonstram os trabalhos de Goulart (2017). Neste sentido, o objetivo da pesquisa é poder identificar e problematizar processos subjetivos associados à novas formas de institucionalização no serviço de saúde do CAPS. A saúde como se propõe este trabalho, procura articular o tempo todo o social com a experiência individual da pessoa, de como ela organizou subjetivamente suas experiências ao longo da vida. Então o que se procura é entender como as diferentes experiências estão configuradas e organizadas na vida daquela pessoa e, portanto, faz sentido pensar em uma saúde como um processo marcado também pelo social (Mori \& González Rey, 2012), para além de uma experiência individual. Nesse sentido, Teoria da Subjetividade pode possibilitar uma visão integradora do social e o individual de maneira processual e dinâmica. A pesquisa se ampara na Teoria as Subjetividade, esta pesquisa foi realizada em um Centro de Atenção Psicossocial do Distrito Federal. Para atingir o objetivo foi utilizado o método construtivo-interpretativo, baseado nos princípios da 


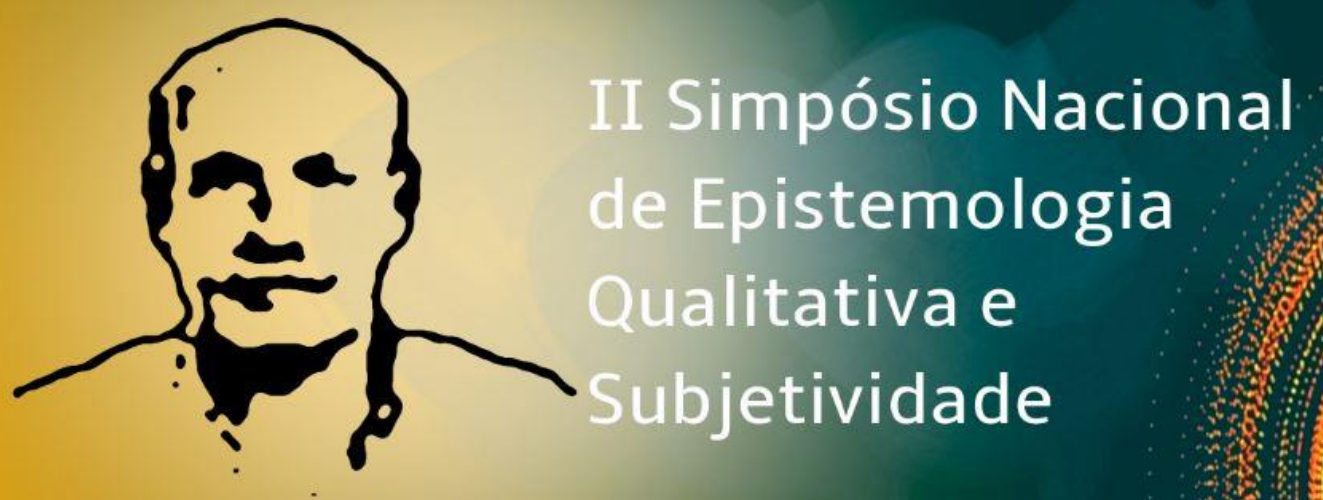

Epistemologia Qualitativa, que entende a produção de conhecimento enquanto processo construtivo-interpretativo, singular e dialógico.- Os participantes da pesquisa são usuários do CAPS e os profissionais que trabalham na instituição. Importante ressaltar que o seguinte trabalho foi aprovado para realização em dois Comitês de Ética. O pesquisador participou de diversas atividades do CAPS desde de: momentos informais com a equipe, atendimentos individuais, participação do grupo de família, visitas aos usuários de saúde mental e reuniões com a equipe. De maneira geral o processo de institucionalização se mostrou bastante presente, desde os aspectos organizacionais com o sucessivo sucateamento dos CAPS no Distrito Federal que levam a superlotação e práticas engessadas; A subjetividade social dominante expressa-se a partir de aspectos associados a medicalização como principal recurso para o usuário assim como pela sua subordinação aos discursos institucionais. Dessa forma, pensamos ser fundamental novas práticas relacionadas à institucionalização. Avançar em relação à forma como as rotinas se configuram superando a ótica de doença e reconhecendo o usuário a partir da forma singular que suas necessidades tomam forma.

Palavras chave: Saúde Mental; Teoria da Subjetividade; Desinstitucionalização.

\section{Referências}

Goulart, D. M. (2017) Educação, saúde mental e desenvolvimento subjetivo: da patologização da vida à ética do sujeito. Tese (Doutorado em Educação) — Programa de Pós-graduação em Educação, Universidade de Brasília, Brasília

Mori, Valéria Deusdará, \& Rey, Fernando González Rey. (2012). A saúde como processo subjetivo: uma reflexão necessária. Psicologia: teoria e prática, 14(3), 140-152. Recuperado em 10 de abril de 2019, de $\underline{\text { http://pepsic.bvsalud.org/scielo.php?script=sci_arttext\&pid=S1516- }}$ $\underline{36872012000300012 \& \operatorname{lng}=p t \& t \operatorname{lng}=\text { pt. }}$ 